\title{
LA TEOLOGÍA MÍSTICA Y EL DES-CONOCIMIENTO DE DIOS
}

\author{
THE MYSTICAL THEOLOGY AND \\ THE DIS-KNOWLEDGE OF GOD
}

\author{
Prof. Manuel Porcel Moreno ${ }^{1}$ \\ Facultad de Teología de Granada, España
}

\begin{abstract}
Resumen: El presente artículo pretende mostrar cómo la teología rationalis y la teología negativa pertenecen y dependen por completo de la metaphysica specialis. Solo desde la teología mística y desde una perspectiva fenomenológica se lograría acceder a la cuestión de Dios sin nuevamente someterlo a un concepto, tal como ha hecho a lo largo de la historia de la filosofía la esencia onto-teo-lógica de la metafísica.
\end{abstract}

Descriptores: Teología negativa · Teología mística - Metafísica de la presencia . Fenomenología

\begin{abstract}
The present article aims to show how the rationalis theology and the negative theology belong and depend completely on the metaphysica specialis. Only from the mystical theology and from a phenomenological perspective would it be possible to gain access to the question of God without again subjecting it to a concept, as the onto-theo-logical essence of metaphysics has done throughout the history of philosophy.
\end{abstract}

Keywords: Negative theology · Mystical theology · Metaphysics of presence Phenomenology

\section{INTRODUCCIÓN}

En fenomenología, ciertamente, se trata de dejar aparecer el fenómeno Dios tal como Él se da y se revela al hombre. Sin embargo, la historia de la filosofía ha pensado siempre a Dios como una ov̉oí $\alpha$ fija más que como una $\varphi v ́ \sigma ı \varsigma$ desbordante que emerge o como una $\alpha \lambda \eta \dot{\eta} \theta \varepsilon ı \alpha$ que constantemente se descubre y se desvela. Es decir, el fenómeno Dios ha quedado a lo largo de los siglos reducido a un ente privilegiado-, considerado siempre dentro del horizonte de aparición del ser del ente. Quizás si se hubiera "pensado" de otro modo, o mejor aún, no pensando conceptualizado-, Dios no hubiera permanecido como en la metafísica encapsulado y limitado dentro del horizonte del ser. Pero ¿hasta qué punto se asemeja el Dios de

\footnotetext{
${ }^{1}$ Profesor de Filosofía de la religión, Teodicea y fenomenología en el Departamento de Filosofía de la Facultad de Teología de Granada. E-mail: mporcel@teol-granada.com
} 
la teología cristiana, en tanto que teología provocada por una Revelación, al "Dios" de la metafísica fijista? O mejor aún, ¿hasta qué punto se confunde el Dios de la Sagrada Escritura con el "Dios" de la teología conceptual?

Trataremos, pues, en adelante, de diferenciar cómo el Dios que se revela ha sido pensado por la filosofía y la teología a lo largo de la historia y cómo podemos acceder a la cuestión de Dios sin nuevamente limitarlo a un concepto. ${ }^{2}$

\section{1. "Metafísica de la presencia" y “TeOlogía negativa"}

Aun surgiendo, en apariencia, de regiones tan diferentes, las dos cuestiones de la "metafísica de la presencia" y de la "teología negativa" acabarían sorprendentemente no solo por encontrarse, sino además por superponerse en gran parte.

Primeramente, se encuentran porque finalizan en aporías paralelas. Ambas cuestiones tienen en común un defecto característico: no solo no tienen una definición precisa, sino tampoco una legitimidad histórica nítida. Por un lado, a nuestro juicio, Heidegger nunca emplea como tal el sintagma "metafísica de la presencia". Ciertamente, el filósofo alemán no deja de cuestionar a lo largo de toda su obra con total radicalidad la constitución onto-teo-lógica de la metafísica y la esencia de la presencia, pero sin llegar nunca a emplear explícitamente dicho término. Derrida que, por el contrario, sí emplea este sintagma, tampoco expone con claridad lo que se puede y debe entender por él. ${ }^{3}$ Pero ¿por qué se identifica siempre la metafísica con o/y por la presencia? Dicho de otro modo, ¿equivale la "presencia" con precisión a la onto-teo-logía? O mejor aún, ¿por qué no podría la metafísica abarcar, por el contrario, la ausencia? Ciertamente, la "metafísica de la presencia" se caracteriza justamente por su indeterminación e imprecisión de fondo. Por otro lado, encontramos que la fórmula "teología negativa" también se caracteriza por una indeterminación similar. Aimé Solignac (1990-1991) sostiene que "Dionisio no emplea nada más que una vez la formula «teología negativa», en

\footnotetext{
${ }^{2}$ No debemos confundir aquí la teología Revelada con la teología rationalis que pertenece y depende por completo de la metaphysica specialis. Del mismo modo que la Revelación de la Sabiduría del Verbo se opone frontalmente a la sabiduría del mundo, así también se contrapone la teología Revelada a la teología rationalis. De hecho, si pretendiésemos establecer que la donación en fenomenología podría unirse a un concepto de donación en teología Revelada, deberíamos distinguir cabalmente esta donación de la donación metafísica y de su causalidad en la medida en que aquella proviene de la teología Revelada, y no de la teología rationalis -filosófica-.

${ }^{3}$ Derrida (1990) emplea esta fórmula para remitir extrañamente a Husserl como pensador de "la fenomenología, metafísica de la presencia en la forma de la idealidad" (p. 9). Podría ser esta crítica por parte de Derrida a la fenomenología husserliana la que haya conducido a fijar finalmente esta cuestión. De hecho, el filósofo franco-argelino (1990) afirmará que "la fenomenología no sería ya de hecho dueña en su casa. La ontología estaría ya en su puesto" (p. 117).
} 
el título del capítulo tercero de la Teología mística" (t. 15, col. 513). En realidad, Dionisio Areopagita no pretende en ningún momento definir la "teología negativa" o establecer si hay una o varias "teologías negativas", sino simplemente saber cuáles son las palabras sobre Dios afirmativas y cuáles son las negativas. De hecho, cuando el Areopagita emplea el término "teología" no es sino para designar las expresiones utilizadas por las Santas Escrituras para decir o no decir a Dios. Es más, ni Ireneo, ni Agustín, ni Buenaventura, ni incluso Tomás de Aquino emplean jamás la fórmula "teología negativa", aun cuando todos ellos no solo recurren a las negaciones para nombrar a Dios, sino además construyen la teoría de la apofasis. Para todos estos filósofos y teólogos del medievo, el término "teología” permanecería muy alejado del concepto de la metafísica. ${ }^{5}$

Finalmente, estas dos cuestiones se superponen, puesto que mantienen una relación mucho más íntima. El mismo Derrida ha reconocido en su conferencia de 1968 "La différance” pronunciada ante la Sociedad Francesa de Filosofía que estas dos cuestiones se entrecruzaban en el centro de su trabajo. ${ }^{6}$ Se trata aquí de una denegación. ${ }^{7}$ Denegación que el filósofo franco-argelino repetirá dieciocho años más

\begin{abstract}
${ }^{4}$ Derrida (1987) con un tono precavido hace cuenta de esta dificultad cuando evoca "lo que se llama, a veces de forma abusiva, la teología negativa" (p. 535). Véase, también: "Bajo el título muy laxo de «teología negativa» se designa frecuentemente una cierta forma de lenguaje, con su puesta en escena, sus modos retóricos, gramaticales, lógicos, sus procedimientos demostrativos, en una palabra, una práctica textual atestiguada o situada en la «historia». (...) ¿Hay una teología negativa, la teología negativa? En todo caso, la unidad de su archivo sigue siendo difícil de delimitar. Se la podría intentar organizar en torno a ciertas tentativas que pasan por ejemplares o explicitas, como la de Los nombres divinos de Dionisio Areopagita (llamado el Pseudo-Dionisio). Pero no cabe estar seguro nunca, y por razones esenciales, como se verá, de poder atribuir a quienquiera que sea un proyecto de teología negativa como tal" (ídem). Por su parte, Jean-Luc Marion (1977) pone en duda la legitimidad del título del cap. III De mystica theologia: "Que sepamos, Dionisio no emplea nada que pueda traducirse por «teología negativa». Si habla de «teologías negativas», en plural, no las separa de las «teologías afirmativas» con las que aquellas mantienen la relación que se ha descrito aquí" (p. 244).
\end{abstract}

${ }^{5}$ Algunos autores señalan que el sintagma "teología negativa" es un concepto moderno. Cuando F. Bourgoing fija la definición moderna de la teología, establece que hay tres tipos de teología: la positiva, la escolástica y la mística. Según él, "la positiva tiene como objeto la interpretación de la Sagrada Escritura; (...) la escolástica clarifica las verdades de la fe como método, incluyendo en ello cierto razonamiento humano; y la mística aplica estas verdades y se sirve de ellas para elevar el alma a Dios" (Bourgoing F., 1644, p. 83). Parece que Bourgoing ignora por completo la "teología negativa" o quizá de un modo sobreentendido la incluya con las otras dos "vías" en la teología mística. Sea como fuere, parece que el origen de este término no está del todo claro. Con relación a esta discusión, véase: Sales, M. 1970. "La théologie négative: méthode ou métaphysique". Axes III/2.

6 "Y sin embargo, lo que se señala así de la diferencia no es teológico, ni siquiera del orden más negativo de la teología negativa; que siempre se ha ocupado de librar, como es sabido, una superesencialidad más allá de las categorías finitas de la esencia y de la existencia, es decir, de la presencia, y siempre de recordar que si a Dios le es negado el predicado de existencia, es para reconocerle un modo de ser superior, inconcebible, inefable" (Derrida, 1972, p. 6).

${ }^{7}$ Véase la discusión de J. L. Marion (1977), p. 318, respecto a esta denegación. Emmanuel Levinas parece realizar una denegación similar cuando describe su concepto de infinito: "Todas las negaciones que intervienen en la descripción de esta «relación al infinito» no se limitan al sentido formal y lógico de la negación, no constituyen una teología negativa" (Levinas, 1979, p. 164). 
tarde en Jerusalén en su conferencia de 1986 "Comment ne pas parler. Dénégations". En esta ocasión, articulará la denegación en tres momentos: en primer lugar, una denegación explícita por la que, según Derrida, la "teología negativa" dice lo que precisamente no pretende decir, a saber, no decir de Dios nada de manera positiva; a continuación, una denegación implícita por la cual, en la opinión del filósofo francoargelino, la "teología negativa" hace lo que precisamente no pretende hacer, esto es, predicar - decir todavía alguna cosa- de Dios y, en consecuencia, reinscribirlo en la cuestión de la "metafísica de la presencia"; 8 finalmente, una denegación explícita realizada por Derrida en la que sostiene con firmeza que él mismo no repite con el concepto de la "différance" el fracaso de la "teología negativa".

Ahora bien, esta última denegación por la que Jacques Derrida niega que la "différance" repita la empresa y los fracasos de la "teología negativa", puesto que aquella solamente pretende deconstruir la "metafísica de la presencia", exige las otras dos denegaciones, esto es, mostrar que la "différance" difiere de la "teología negativa" porque esta siempre permanece sometida al privilegio de la presencia. Es más, podríamos sugerir incluso que la "teología negativa" con su pretexto de "honrar por el silencio" no conduce más que a un ateísmo radical. ${ }^{10}$ En definitiva, la "teología negativa" afirma -negando- a propósito de Dios sin llegar jamás a pensarlo fuera del horizonte de la "metafísica de la presencia".

Organizaremos este argumento fundamental a partir de tres objeciones dirigidas a la "teología negativa". La primera objeción establece que la "teología negativa" no niega, en realidad, la esencia, la verdad o el ser de Dios, sino que

\footnotetext{
${ }^{8}$ Pudiera ser que al intentar determinar el ser de Dios a partir de lo que Él no es, la "teología negativa" lograra precisamente lo contrario de lo que pretende, puesto que si piensa la trascendencia absoluta de Dios como un estatuto ontológico excepcional completamente contrario a nuestro modo de ser a fin de cuentas solamente está pensando el no ser de Dios como un no ser -a la medida de lo- humano. Es decir, el ser divino, que es de un modo absoluto, continuará siendo pensado a partir del ente. Eso sí un ente al que se le atribuye un estatuto superior al de todo ente, a saber, un ser mas allá del ser. Al fin y al cabo, no se tratará más que de un "Dios" sometido nuevamente a la esfera del ser, o sea, un nuevo "Dios" idolátrico.
}

${ }^{9}$ Neologismo de Jacques Derrida basado en que el término diferencia (différence) contiene también un diferimiento (différance) en cuanto una palabra solo puede ser plenamente entendida mediante su diferimiento hacia otras palabras que la expliquen. Ciertamente, el filósofo franco-argelino no siempre deja claro que su proyecto de la deconstrucción no pueda no entenderse como una suerte de "teología negativa". El mismo deja plantear alguna sombra de duda sobre esta cuestión cuando en la breve Carta a un amigo japonés le responde al profesor Izutsu que "se ha afirmado precipitadamente que $<$ la deconstrucción $>$ era una especie de teología negativa. Esto no es verdadero, ni tampoco falso, pero dejo aquí este debate" (Derrida, 1997, p. 25).

${ }^{10}$ Así lo afirma recientemente C. Bruaire (1974): "Es necesario pues tomar nota de la teología negativa, darle su estatuto exacto, distanciado de los sentimientos fideístas, que recubren con un caparazón sensible, de residuos religiosos, el absoluto inalterable, signado del Nada (Rien); la teología negativa es negación de toda teología. Su verdad es el ateísmo" (p. 21). Encontramos un eco de esta perspectiva en el pensamiento derridiano cuando parece sugerir que "la apofasis inclina casi al ateísmo" (Derrida, 1993, p. 18). Véase un posicionamiento contrario a esta brutal asimilación, en: De Lubac, H. (1945). De la connaissance de Dieu. Paris: Ed. de Temoignage Chrétien. 
únicamente los "niega" para restablecerlos aún con más fuerza. Su negación desembocaría finalmente en una quasi-afirmación, es decir, su negatividad se transformaría en afirmación -una sentencia, un veredicto, una declaración-. Al contrario de la "teología negativa", la teología mística no restablece in fine lo que ha negado, sino que pretende transitar a través de la via eminentiae desde la predicación afirmativa y/o negativa de Dios a una palabra no predicativa del mismo. La segunda objeción señala que la "teología negativa" se inscribiría finalmente en el horizonte del ser, puesto que no se trataría más que de un nuevo "Dios" idolátrico pensado a partir del ente y sometido nuevamente a la esfera del ser. La teología mística, en cambio, no determina a Dios por el ser, puesto que este ni cualquier otro nombre alcanzan ni a lo que es propio de Dios ni a Dios propiamente. La finalidad a la cual aspira la teología mística no consiste sino en pensar a Dios "de otro modo que ser”, sin predicar -afirmar o negar- de Él nada que sea. La tercera objeción fija que la "teología negativa" acaba convirtiéndose en una "filosofía cristiana", ya que al determinar el ser de Dios a partir de lo que Él no es, solamente está pensando el no ser de Dios como un no ser - a la medida de lo- humano, tal como de un modo u otro lo piensa la onto-teo-logía. Sin embargo, la teología mística no acabaría inscribiendo a Dios dentro de la esencia onto-teo-lógica de la metafísica, puesto que no cumple ninguno de los requisitos o características necesarias para establecer una onto-teo-logía.

Estas objeciones que señalamos obligan a la teología cristiana, en tanto que teología provocada por una Revelación, a cuestionarse, primeramente, en qué medida la teología negativa no está intentado restablecer lo que la apofasis ya había descalificado aparentemente y, finalmente, si la teología cristiana podría sustraerse a la "metafísica de la presencia" o más bien estaría abocada a reducirse a ella en último término. En lo sucesivo, intentaremos responder estas dos cuestiones abordando de lleno cada una de estas tres objeciones.

\section{MÁs ALlÁ DE TODO NOMBRE}

Comenzaremos confrontando la primera objeción -la negación restablece implícita y subrepticiamente una afirmación- con el Corpus Areopagiticum o Dionisiacum, en especial con los dos tratados De divinis nominibus y De mystica theologia, para confirmar que la teología mística ni nombra ni no-nombra, sino, por el contrario, des-nombra a Dios.

Ciertamente, podemos observar cómo para el Areopagita la negación no es suficiente por sí sola para definir una teología. Ahora bien, esto no quiere decir que aísle la "teología negativa" como tal, sino más bien que usa la apofasis para incluirla en un conjunto que comprende no solo dos momentos - afirmación y negación- sino 
tres -afirmación, negación y eminencia-. Por tanto, la vía afirmativa no compite como en un duelo cara a cara con la vía negativa ni viceversa sino que la una y la otra ceden finalmente ante una tercera vía. ${ }^{11}$ Esta doctrina conjugará tres términos diferentes e irreductibles los unos a otros. En efecto, esta triplicidad de las vías articulará y dominará la causa -vía afirmativa-, la incomprensibilidad de Dios vía negativa- y la eminencia -vía superlativa-. En lugar de un duelo, la cuestión consistirá en el restablecimiento de una triplicidad. Pues, ¿de qué sirve el aferrarse a una oposición frontal entre la via causalitatis - afirmativa- y la via remotionis negativa-, en vez de desplegar, al menos como posibilidad, una tercera vía en la que no solo se conjugue la afirmación y la negación, sino además se trascienda la una y la otra? ${ }^{12}$

Tomás de Aquino comienza, en contra del procedimiento dionisiaco, por los nombres negative para reconocerles una preeminencia con respecto a los nombres absolute et affimative de Dios. Sin embargo, para el Areopagita, tanto la afirmación como la negación conducen a la eminencia, puesto que Dios no se deja nombrar únicamente como la Causa de las perfecciones ni solamente como el Incognoscible. Él trasciende todo lo conocido y también todo lo desconocido (Martín, 2001, pp. 39-46). De este modo, la tercera vía superaría las insuficiencias de las dos primeras. Esta se desplegará más allá de la oposición entre la afirmación y la negación, en definitiva, entre lo verdadero y lo falso. En adelante, ya no se tratará de afirmar o negar un predicado de un sujeto, sino más bien de transgredir y superar el duelo de los dos valores de verdad -afirmación y negación- en los cuales se ejercita toda la lógica de la metafísica. Es cierto que Dionisio ha pensado explícitamente la relación

\footnotetext{
11 "Ciertamente, no podemos afirmar como verdadero que conocemos a Dios por su Naturaleza, pues es imposible conocer esto, ya que supera toda razón e inteligencia, sino que partiendo del orden de todos los seres, puesto que ha sido prestablecido por Él y posee cierta imagen y semejanza de sus ejemplares divinos < vía afirmativa >, nos elevamos por el camino y orden que nos es posible hasta Él que está por encima de todos $<$ los entes $>$, mediante la privación y abundancia de todo $<$ vía negativa $>$ y mediante la Causa $<$ el Requisito $>$ de todo $<$ tercera vía $>$. Por tanto, a Dios se le puede conocer en todas las cosas y fuera de todas ellas" (Areopagita, P.G. 3, 869d-872a). "Es necesario atribuir y decir de la Causa <el Requisito $>$ todo lo que se afirme de los seres, por ser la causa de todos ellos, y todo eso decirlo de Ella más propiamente, porque es supraesencialmente superior a todas las cosas, y no debemos creer que las negaciones sean algo que contradice las negaciones, sino que la Causa $<$ el Requisito $>$, que está por encima de toda negación o afirmación, existe mucho antes y trasciende toda privación" (Areopagita, P.G. 3, 1000b). “(...) pues la Causa <el Requisito> perfecta y única de todas las cosas está por encima de toda afirmación y también la trascendencia de quien está sencillamente libre de todo está por encima de toda negación y más allá de todo" (Areopagita, P.G. 3, 1048b).

${ }^{12}$ No es objeto de este ensayo establecer un vínculo entre la teología de Dionisio Areopagita y lo que será posteriormente la lógica dialéctica de Hegel. Pero, en cierta manera, la lógica dialéctica hegeliana está inspirada en el evangelio de san Juan y en la posterior especulación teológica trinitaria. Recordemos el viernes santo especulativo: Dios - posición plena de realidad- se niega a sí mismo en la kénosis y en la muerte del hijo en la cruz -negación de Dios en la cruz- y se recupera a sí mismo en la resurrección, ascensión, glorificación y efusión del espíritu -Dios se completa a sí mismo-. Sin adentrarnos más en ello, solo lo dejamos aquí apuntado como una posible vía de estudio.
} 
entre afirmación y negación, pero siempre mirando a lo que permanece "por encima de todas las negaciones y afirmaciones" y, por tanto, "por encima de todas las privaciones" (Areopagita, P.G. 3, 1000b).

Así, pues, todos los nombres atribuidos a Dios, incluso los más elevados, se encontrarían descalificados. Es esta la razón por la que sugerimos que no hay ningún nombre propio ni apropiado a Dios ${ }^{13}$. No se trata de nombrarlo ni de no nombrarlo sino más bien de des-nombrarlo. De hecho, la multiplicidad de nombres atribuidos a Dios equivale en este caso al anonimato ${ }^{14}$. La des-nominación no tratará más que de despojarlo, eximirlo y liberarlo de toda nominación. En otras palabras, intentará deshacer ese decir del nombre rechazando toda función nominativa y negando toda pertinencia a la predicación. Esta des-nominación suspende finalmente el imperio de los dos valores de verdad -afirmación y negación- entre los cuales se desplegaba toda la lógica de la metafísica. Para lograr esta des-nominación, el Areopagita propone asignarle a Aquel que sobrepasa toda nominación el título de aitì. Ahora bien, la aĩì de la que aquí se habla no podrá ser entendida jamás como la "causa" metafísica, sino más bien como el Requisito que requerirían ( $\alpha i \tau \dot{\varepsilon} \omega)$ todos los requerientes ( $\alpha i \tau i \alpha \tau \alpha ̀)$. Al sobrepasar tanto la afirmación como la negación, la aitì no pretende afirmar o negar un nombre de Dios, sino, por el contrario, romper con toda posible función predicativa o designativa del lenguaje. ${ }^{15}$ En la opinión de Marion (2010), p. 178, "con la tercera vía, no solamente no se trata ya de decir (o de negar) algo de algo, sino de no decir ni desdecir más -se trata de referirse Aquel al que la nominación ya no le alcanza, tampoco de decir el referente, sino de referir pragmáticamente el que dice (locuteur) al Referente inaccesible". En definitiva, atribuir un nombre a Dios implicaría necesariamente identificarlo en su esencia y a su esencia y, por tanto, someterlo definitivamente a la "metafísica de la presencia".

13 “(...) ni uno ni unidad, ni divinidad ni bondad, ni espíritu, como lo entendemos nosotros, ni filiación ni paternidad ni ninguna otra cosa de las conocidas por nosotros o por cualquier otro ser. No es ninguna de las cosas que no son ni tampoco de las que son, ni los seres la conocen tal como es" (Areopagita, P.G. 3, 1048b).

14 “(...) aquel que es alabado múltiplemente bajo múltiples nombres, las Escrituras lo llaman inefable y anónimo" (Areopagita, P.G. 3, 865c). Véase, también: Areopagita, P.G. 3, 596a-b. Dionisio Areopagita se inspira aquí en varias citas de la Sagrada Escritura, entre ellas señalamos: Gn 32, 30 -el ser misterioso del Yaboc se niega a decir su nombre-, Jue 13, 17 -el ángel no accede tampoco a dar su nombre-, Ex 3,13 -ante la pregunta de Moisés a Dios por su nombre, Dios le responde: "Yo soy el que soy"- y Flp 2,9 -Dios le atribuye a Jesús el Nombre de Señor, como el Nombre que está sobre todo nombre-.

15 " $<$ Como $>$ el aítìov de todas las cosas, él mismo no es ninguna de ellas, en tanto que trasciende sobreesencialmente a todas las cosas" (Areopagita, P.G. 3, 593c-d). "También se le puede conocer a Dios mediante el conocimiento y la ignorancia. Y de Él existe pensamiento, razón, ciencia, tacto, sensación, opinión, imaginación, nombre y todas las otras cosas, pero ni le entendemos, ni le encerramos en palabras ni le nombramos, no es ninguno de los seres ni puede ser conocido en ninguno de ellos" (Areopagita, P.G. 3, 872a). "De Él se predica todo simultáneamente y a la vez no es nada de todo eso" (Areopagita, P.G. 3, 824b). 


\section{MÁs ALLÁ DEL SER}

Se hace posible ahora abordar la segunda objeción -la "teología negativa" acabaría finalmente inscribiéndose en el horizonte del ser-para cuestionarnos a su vez si la teología mística también se inscribe en dicho horizonte.

Ciertamente, en el Corpus Dionisiacum, Dios no permanece determinado por el ser. Para el Areopagita, ni el ente ni el ser ofrecen un nombre propio o impropio de Dios. En efecto, Dios, en tanto que Bondad y aìì (Requisito) universal, designa "el principio de los entes, a partir del cual se caracterizan tanto todos los entes cualesquiera sea, como el ser mismo y todo principio" (Areopagita, P.G. 3,821 b.). ${ }^{16}$ De hecho, a partir de las dos obras que principalmente venimos analizando, podemos extraer las siguientes tesis: en primer lugar, que el horizonte del ser permanece únicamente de un modo regional, puesto que por definición deja fuera de sí a todos los no-entes; en segundo lugar, que los no-entes, incluso no siendo, se refieren al bien bajo el modo del deseo $;{ }^{17}$ en tercer y último lugar, que la primera (o la última) de las des-nominaciones de Dios no deberá extraerse del horizonte del ser, sino más bien del horizonte del bien, pero sabiendo que esta y cualquiera de todas las otras des-nominaciones no alcanzan ni a lo que es propio de Dios ni a Dios propiamente. ${ }^{18}$

Ahora bien, para pensar verdaderamente la transgresión del horizonte del ser no basta con declarar que la instancia de la Bondad trasgrede dicho horizonte. Aun cuando sea "el más venerable de los nombres" (Areopagita, P.G. 3, 977c y 981b), Dionisio no concede ningún privilegio esencial a la Bondad. Es evidente que, en el Corpus Areopagiticum, la Bondad transciende en principio el ser, pero de ello no se deriva que alcance la esencia, sino que, a pesar de tener una cierta preeminencia con respecto a los otros nombres, la Bondad flota, por así decir, entre los nombres derivados y el innombrable. Ya no se trata solamente de pensar a Dios sin el ser, sino sobre todo de pensarlo "de otro modo que ser". Sin embargo, podrían objetarnos aquí que más allá del ser no podríamos pensar -ni bajo la desnominación de la Bondad ni de cualquier otra-. Pero ¿deberíamos tomar en serio este reproche o más bien considerarlo como absurdo? En efecto, que la teología mística y su tercera vía no sepa o no quiera decirnos que es ese "otro modo que el

\footnotetext{
${ }^{16}$ Podemos referirnos aquí también al texto de Juan Damasceno: "Decir de Dios lo que es por esencia es imposible. Es más apropiado elaborar un discurso <acerca de Él> mediante la suspensión de todo. Porque Él no es nada de los entes, no como no siendo, sino como siendo por encima de todos los entes e incluso siendo por encima del ser mismo" (P.G. 94, 800b).

17 "Si se permite hablar de este modo incluso el no-ente desea el bien que se encuentra por encima de todos los entes" (Areopagita, P.G. 3, 697a).

18 “El nombre divino < la des-nominación divina> «Bien» manifiesta en totalidad todas las emanaciones provenientes de la $\alpha i$ ì $\alpha$ de todas las cosas y se extiende a los entes como también a los no-entes, sobrepasando los entes y los no-entes" (Areopagita, P.G. 3, 816b).
} 
ser" no puede tomarse como una objeción sino como la finalidad a la que aspira. Recordemos que la tercera vía no pretende nombrar ni afirmar (o negar) a Dios, esto es, predicar cualquier cosa que sea conocida o desconocida de Él.

Es más, si esta predicase cualquier cosa que sea, debería ello que reprochárselo precisa y legítimamente como una contradicción. Es justamente la imposibilidad de decir algo -afirmar o negar- sobre lo que es o podría ser Dios lo que marca y caracteriza tanto la transgresión del ser como la superación de la predicación. En palabras de Jean-Luc Marion (2010):

Se trata de exponer en su mira a un no-objeto, hasta el punto de recibir de él determinaciones tan radicales y nuevas que me dicen y me educan infinitamente más de lo que ellas me enseñan e informan. En adelante, las palabras no me dicen ni me explican ya nada sobre algún cara a cara reservado por y para mi mirada; ellas me exponen a mí mismo a lo que no se deja decir sino es para permitirme precisamente no decirlo, sino reconocerlo como Bondad, por tanto, amarla. (p. 185).

De este modo, podemos concluir que la suspensión de toda posible predicación atestigua el fracaso de la transgresión hacia el "de otro modo que ser", puesto que la tercera vía ni abre ni puede abrir ningún nuevo predicado dicho, no-dicho o predicho sobre Dios más allá del ser o "de otro modo que ser". ${ }^{19}$

\section{MÁS ALLÁ DE LA ESENCIA}

Abordamos, por último, la tercera objeción -la "teología negativa" inserta a Dios en la esencia onto-teo-lógica de la metafísica- para mostrar que la teología mística no solo no inserta a Dios en la onto-teo-logía, sino que además no cumple estrictamente ninguno de sus requisitos.

La esencia onto-teo-lógica de la metafísica se caracteriza por definirse según tres caracteres bien precisos: a) la determinación de "Dios" a partir del Ser del ente o a partir del concepto de ente; b) la fundación causal por parte de Dios de todos los entes comunes; c) la fijación de "Dios" como causa sui, a saber, como el ente supremamente fundador que se funda a sí mismo. Ahora bien, ¿incluye realmente Dionisio Areopagita a Dios dentro del horizonte de la metafísica y, en consecuencia, dentro de la cuestión del ser del ente o, por el contrario, piensa a Dios sin y más allá de la esencia?

En efecto, el Areopagita afirma en De divinis nominibus que Dios no solo es "el principio de los entes", sino que, además, es aquello de lo que procede el ser y que, a su vez, él mismo (Dios) no procede del ser (P.G. 3, 821b). Por consiguiente, tanto el ente como la enticidad es precedida por Dios, puesto que él mismo es el

\footnotetext{
${ }^{19}$ En adelante, ya no se tratará de decir o de nombrar sino de escuchar la llamada anónima de Dios.
} 
principio del ser y distinto del ente. ${ }^{20}$ Dios no solamente no equivale al ser, sino que este remite a Dios. Por tanto, no solo entre Dios y los entes existe una discontinuidad esencial, sino también entre el ser de los entes y Dios. La trascendencia de Dios no puede apresarse en el horizonte del ser, pues dicha trascendencia se ejerce también sobre él. Resulta totalmente evidente que, si el ser de los entes surge de Dios, este no puede determinarse ni comprenderse ni desde el ser ni desde los entes.

Recordemos también que aun cuando Dionisio le asigne a Aquel que sobrepasa toda nominación el título de aìì, esta no podrá ser entendida jamás como la "causa" metafísica, sino más bien como el Requisito que requerirían ( $\alpha i \tau \dot{\varepsilon} \omega)$ todos los requirentes ( $\alpha i \tau i \alpha \tau \grave{\alpha}$ ). Con todo, Dios no se deja nombrar únicamente como la Causa de las perfecciones (via causalitatis) ni solamente como el Incognoscible (via remotionis). Él trasciende todo lo conocido y también todo lo desconocido. Así, pues, conocer a Dios no conlleva cabalmente conocerlo a partir de un concepto de su esencia divina, sino conocer que la imposibilidad de comprender a Dios mismo es precisamente su conocimiento adecuado. En definitiva, Dios está así más allá del ente, del ser, de la esencia y del mundo. Constatamos, finalmente, que la teología mística, al menos en el Corpus Dionisiacum, no satisface por completo estas tres exigencias que inscribirían a Dios en la onto-teo-logía y lo identificaría a partir de un pensamiento estricta y explícitamente metafísico.

\section{El Des-CONOCIDO}

Fue a partir de la escolástica tardía cuando se produjo la separación entre filosofía y teología. Hasta entonces ambas cuestiones habían estado estrechamente unidas dentro del mundo cristiano. La filosofía era la sierva de la teología y el medio para la expresión teológica. El pensamiento filosófico argumentaba y justificaba los procesos místicos de ascensión hacia Dios y la teología mística se consideraba como el supremo conocimiento de Dios.

Ahora bien, precisamente, por esta razón, ¿es tan obvio que la teología y los teólogos de los primeros siglos e, incluso, los del medievo no hayan verdaderamente intentado cumplir aquello que ellos mismos decían emprender -la tercera vía- y hayan sucumbido, por el contrario, ante la fascinación metafísica en la que toda nominación catafática de Dios acabaría convirtiéndose en una quasi-afirmación que integraría finalmente la cuestión de Dios en la presencia? ¿No tiene la teología, desde el punto de vista de la Revelación, los medios y la intención de pensar la cuestión de Dios más allá de la "metafísica de la presencia" para no ceder banalmente ante ella?

\footnotetext{
20 "Y el Ser en sí procede del que es Ser antes y el Ser procede de Él y no Él del ser, y en Él está el Ser y no Él en el Ser, el Ser le tiene a Él y Él no contiene al Ser, Él es la eternidad, el principio, y la medida del Ser por existir antes que la esencia, que el ser, que la existencia y que la eternidad, y es principio creador, el medio y el fin de todas las cosas" (Areopagita, P.G. 3, 824a).
} 
Son muchas las razones que nos permiten afirmar que el pensamiento dionisiano está tensionado por una doble constatación filosófico-teológica. Esta doble constatación podríamos caracterizarla desde la emblemática distinción que la escolástica hace entre lo dado in re y lo dado in intellectu. Por una parte, Dios se revela in re, sobre todo, como hiperesencial (hyperousios). Dios excede tanto la sustancia como su régimen. En efecto, el modus essendi de Dios sería, paradójicamente, no ser al modo en que los seres son. Él está así más allá de todos los entes, del ser mismo, e incluso, del mundo, puesto que permanece "segregado hiperesencialmente de todas las esencias" (Areopagita, P.G. 3, 649b-651a). Por otra parte, Dios se revela in intellectu, sobre todo, como impensable (anoetós) e inefable (arrêtos). El intelecto humano tan solo puede conocer el ente y sus modos. Por tanto, para pensar la trascendencia divina sería necesario "un pensamiento más allá del ser, un pensamiento que piense más allá de lo que piensa" (Levinas, 1994, p. 150). Asimismo, para hablar de Dios sería necesario un lenguaje que pudiera decir más de lo que dice o quizá, simplemente, dejar de hablar. Frente a la imposibilidad de un conocimiento humano de Dios, Dionisio Areopagita sostiene que únicamente la divinidad sería la que "podría decirse a sí misma con propiedad y con perfecto conocimiento" (P.G. 3, 585b-588b). De un modo similar, Tomás de Aquino afirmará en la Summa Theologiae que Dios in se es máximamente inteligible, pero quoad nos es inaccesible (S. Th. I, q. 2, a. 1).

Así, pues, el Areopagita insistirá en que "a Dios se le puede conocer en todas las cosas y fuera de todas ellas. También se le puede conocer a Dios mediante el conocimiento y el des-conocimiento (...) y el conocimiento más divino de Dios es aquel que se conoce por des-conocimiento" (P.G. 3, 872a). Su pretensión no consiste sino en mantener a Dios fuera de toda posible nominación. Ciertamente, Dios no puede hundirse en la presencia, puesto que "a Dios nadie le ha visto jamás" $\left(\right.$ Jn 1, 18) ${ }^{21}$ Nada ni nadie podría soportar su gloria sin perecer. Dios continúa siendo Dios aun cuando se ignore o des-conozca su esencia, su concepto y su presencia, pues un "Dios" que fuese comprendido mediante un concepto no merecería el título de Dios. Por tanto, Dios permanece como Dios solo bajo la condición de establecer y admitir definitivamente la imposibilidad de ser conocido conceptualmente. ${ }^{22}$

De hecho, si hacemos un breve recorrido por la teología cristiana desde los primeros siglos hasta el medievo, observaremos cómo para los filósofos y teólogos de aquella época Dios no puede nombrarse ni conocerse según la presencia. Así,

\footnotetext{
${ }^{21}$ Véase, también: “(...) apartaré mi mano, para que veas mi espalda; pero mi rostro nadie puede verlo” (Ex 33, 23).

${ }^{22}$ La idolatría de la vista -ídolo visible- equivale a la idolatría del concepto -ídolo conceptual-. Ambas idolatrías solo tratan de alcanzar a Dios para mantenerlo aprisionado como un objeto del mundo bajo la mirada o el concepto. La Revelación de Dios trata, en cambio, de superar esta doble idolatría y sus respectivas blasfemias.
} 
Justino afirmaba en el siglo II que "nadie puede decir un nombre acerca del Dios inefable" (P.G. 6, 421b). Ya Orígenes sostenía que "Dios es incomprensible e inconmensurable" (P.G. 11, 124a). ${ }^{23}$ Atanasio, por su parte, subrayaba que "el Dios bueno y amigo de los hombres (...) es invisible e incomprensible por naturaleza, permaneciendo más allá de toda esencia engendrada" (P.G. 25, 69a). Podemos observar cómo la "pragmática teológica de la ausencia" se opone frontalmente a la "metafísica de la presencia" en Hilario de Poitiers, quien afirmaba que "Dios tal como es, y su grandeza, no se dice. La ciencia perfecta consiste en saber a Dios de tal modo que se sepa que no se le puede narrar, aunque no se lo pueda ignorar" (P.L. 10, 57a). ${ }^{24}$ De un modo similar, Gregorio de Nisa escribía que "en eso se halla el verdadero conocimiento de lo que se busca $<$ a saber, ver al Dios invisible e incomprensible>, en que verle consiste en no-ver, porque lo que se busca sobrepasa todo conocimiento, como envuelto por todas partes por una nube de incomprensibilidad" (P.G. 44, 377a). Esta imposibilidad de ver a Dios era reiterada también por Juan Damasceno que expresaba que "nadie ha visto nunca a Dios. El hijo unigénito que está en el seno del Padre Él mismo lo ha enseñado. Lo divino es inefable e incomprensible" (P.G. 94, 800b).

Pero fue Agustín de Hipona quien asentó con gran ahínco que Dios solo puede conocerse no conociéndolo. ${ }^{25}$ El Verdadero conocimiento acerca de Dios comienza cuando cesa la comprensión. ${ }^{26}$ De este modo, tanto el filósofo como el teólogo cristiano han de llevar a cabo la des-nominación para oponerse por completo a la puesta en presencia supuesta de Dios. Ambos saben que el hombre no logrará jamás conocer a Dios tal como Él mismo se conoce a sí mismo. La pretensión de conocer a Dios en su esencia no solo es imposible, sino además indecente. Apoyándonos en Anselmo de Canterbury, podríamos cabalmente mantener que aún

\footnotetext{
${ }^{23}$ Igualmente, Juan Crisóstomo, repetía casi literalmente que "la esencia de Dios es incomprensible" (P.G. 48, 733).

${ }^{24}$ Como veremos más adelante, la "pragmática teológica de la ausencia" no tiene otro fin más que el de defender y excluir a Dios de la presencia.
}

25 “(...) a propósito de este Dios altísimo, que es mejor conocido si no se le conoce (...)” (Agustín, P.L. $32,1015)$. Este conocer no conociendo no trata ni de conocer ni de no conocer con la intención disimulada de conocer todavía. No se trata, en ningún momento, de una catafasis mal enmascarada como apofasis, que abriría a un conocimiento de otro tipo. La tercera vía, que aúna la apofasis y la catafasis en la via eminentiae, trata de conocer por la ignorancia misma, esto es, conocer la incomprensibilidad como tal.

26 "Hablamos de Dios, ¿qué hay de extraño en que no lo hayas comprendido? Porque si lo comprendes, eso no es Dios. (...) Alcanzar algo de Dios, por pequeño que sea, mediante el espíritu, eso es la beatitud; pero comprenderlo es absolutamente imposible" (Agustín, P.L. 38, 663). Pretender conocerle como conociéndole supondría, por el contrario, la aprehensión conceptual de la cuestión de Dios. Podemos hacer referencia aquí a la extravagante pretensión de Spinoza (1915) que afirmaba taxativamente que "el espíritu humano tiene el conocimiento adecuado de la esencia eterna e infinita de Dios" (II, § 47). 
en el caso en el que llegásemos a comprender a Dios como tal, esto es, nombrarlo según su esencia, no alcanzaríamos nunca a conocerlo inmediatamente como tal. Solo conoceríamos algo -alguna cosa- menor que Dios, puesto que en seguida podríamos concebir otro mayor que el que comprendemos y nombramos. ${ }^{27}$ Para descubrir, por tanto, el verdadero conocimiento o, mejor aún, el des-conocimiento de Dios, aquel -el conocimiento- ha de elevarse a sí mismo hasta alcanzar el no conocimiento. Un conocimiento que sea capaz de reconocer lo incomprensible y respetar la des-nominación de Dios como "id quo maius cogitari nequit". ${ }^{28} \mathrm{El}$ propio Tomás de Aquino (1953) sostiene en De potentia que Dios permanece oculto e ignorado, puesto que "eso mismo que es la sustancia de Dios permanece más allá de nuestro entendimiento y por ello nos es ignoto; y esta es la razón por la cual la cumbre del conocimiento humano a propósito de Dios consiste en saber que el conocimiento no lo conoce" (q. 7, a. 5, ad. 14). Incluso para el Aquinate, la

\footnotetext{
${ }^{27}$ Descartes (1996) afirma que la comprensión y el conocimiento sometería a Dios a una concepción finita retrotrayéndolo al nivel de un espíritu finito -el nuestro-. La razón formal de Dios es justamente su incomprensibilidad (A.T. VII, p. 368). Nuestra pretensión no consistirá sino en sugerir un des-conocimiento infinito de Dios más allá de toda posible comprensión. De este modo, jamás podría alcanzarse algo mayor de "aquello mayor que lo cual nada puede pensarse". Pues, si lográsemos comprender a "Dios", este siempre permanecería menor y por debajo de Aquel al que jamás lograríamos comprender. De hecho, aunque el tratamiento anselmiano acerca de la cuestión de Dios es un tratamiento metafísico $\mathrm{y}$, por tanto, es un pensamiento aferrado a la enticidad y a la objetidad, sin embargo, hay un momento en el que san Anselmo parece desfondar la metafísica hacia un horizonte de nulidad fenoménica que de algún modo podría compaginarse, dentro de la lejanía y de los diferentes matices, salvadas las distancias, con la saturación de la que habla la fenomenología marioniana. El hecho de que la metafísica se desfonde al hablar del fenómeno Dios y no pueda hacerse cargo de él, puesto que en el pensamiento de Anselmo aquel mayor que el cual no puede pensarse otro en el fondo es el que no puede ser pensado, es decir, el que no puede ser objetivado ni entificado, ya de alguna manera está apuntando a lo que luego será la saturación. El fenómeno Dios satura el pensamiento humano creado y finito y, efectivamente, impide su conceptualización y su entificación. Para un estudio in extenso, véase: Porcel, M. (2015). “Son realmente onto-teo-lógicas las pruebas clásicas de la existencia de Dios?”. Proyección: Teología y mundo actual (259), pp. 423-444.
}

${ }^{28}$ Para Anselmo, "id quo maius cogitari nequit o aliquid quo maius nihil cogitari possit" significa que solamente se puede pensar a Dios como algo que no se puede concebir, como lo que trasciende todo concepto creado y finito. La cuestión de Dios solamente se abre en el pensamiento cuando este se enfrenta a sus propios límites a la hora de concebir a Dios. Por tanto, mientras el pensamiento conciba a Dios a través de conceptos, este no puede surgir. Dios comienza tan pronto como el pensamiento creado y finito choca con sus propios límites y no puede ir más allá. En la opinión de Miguel García-Baró (2009), p. 252, "el llamado «argumento ontológico» trata de expresar el autotrascendimiento de la razón humana hacia la verdad que la ilumina y que es, como dice la extraordinaria formula de Agustín, interior intimo meo et superior summo meo, o sea, más íntimo que mi mayor intimidad y más alto que lo más alto que hay en mí". Según Marion, en realidad, Anselmo de Canterbury no pretende a través de un concepto ("id quo majus cogitari nequit") definir a Dios, ni conducirnos a un ser o ente trascendente, sino más bien trata de señalar los límites del pensamiento humano cuando este trata de concebir a Dios a partir de conceptos, al igual que cuando trata de pensar más allá de los propios límites del pensamiento humano. Esta máxima pretende poner más de manifiesto la finitud humana que la posibilidad de pensar a Dios. Coloman Etienne Viola (1972), p. 153, escribe al respecto: “C'est à tort qu'on identifie souvent l'argument d'Anselme avec la preuve cartésienne ou leibnizienne, qui part de l'idée de Dieu conçu comme ens perfectissimum, l'idée du plus parfait (...) En effet, chez Anselme, il ne s'agit pas de l'analyse d'un concept comme chez la plupart des partisans de l'argument ontologique", sino "(...) d'une analyse de notre manière de comprendre Dieu que celle d'un simple concept". 
teología no tiene la pretensión de nombrar en propiedad a Dios, sino más bien de conocerlo a título de lo que no se conoce. Por consiguiente, la des-nominación no desemboca en una "metafísica de la presencia", ya que no trata sino de liberar a Dios de cualquier inclusión en la presencia. En la opinión de Marion (2010), p. 191, "la incognoscibilidad conocida como tal descalifica pues cualquier posible primado de la presencia respecto a Dios". La des-nominación desemboca, en cambio, en una "pragmática teológica de la ausencia". ${ }^{29}$ En efecto, la teología de la via eminentiae no tiene otra intención más que la de manifestar a Dios en la escucha de esta ausencia. Aquí el Nombre se da como no dando la esencia, esto es, sin nombre ni presencia. En este caso ya no se podría hablar como en el de la teología afirmativa y negativa de onto-teo-logía, puesto que no solo falta el nombre y la esencia, sino también el concepto de ser y la presencia. El nombre sobrepasa todo nombre, designa lo que no se puede nombrar. De este modo, el Nombre no inscribe ya a Dios en el horizonte de nuestra predicación, sino, por el contrario, nos inscribe a nosotros mismos en el horizonte propio de Dios. Así, pues, la teología mística no pretende darle un nombre a Dios sino dejar que nosotros recibamos el nuestro del Nombre des-conocido. En definitiva, "el nombre que esta sobre todo nombre" (Flp 2, 9) no solo des-nombra a Dios y lo excluye de toda predicación, sino sobre todo posibilita la escucha y el dejarnos nombrar a partir de su llamada anónima. En la opinión del filósofo francés (2010), p. 198, “el teólogo tiene como función callar el Nombre y así dejarle darnos uno, mientras que el metafísico tiene como obsesión reducir el Nombre a la presencia, con el fin de vencerlo".

\section{DiOS COMO FENÓMENO SATURADO POR EXCELENCIA}

Queda aún por descubrir el fenómeno saturado por excelencia al que la teología mística intenta de este modo hacer justicia. Advertimos que no se trata aquí de decidir la eficiencia de este fenómeno, sino solamente de concebir su posibilidad formal, esto es, el tipo de fenomenicidad que lo haría pensable y que exige tanto la "ausencia de los nombres divinos" como la "pragmática teológica de la ausencia". ${ }^{30}$ Ahora bien, ¿cómo podríamos describir este fenómeno saturado por excelencia haciendo justicia a su posibilidad? O mejor aún, ¿cómo podríamos

\footnotetext{
${ }^{29}$ Según el pensamiento marioniano, la "pragmática teológica de la ausencia" no pretende establecer la no presencia de Dios sino el hecho de que el Nombre que se da a Dios tiene como función no solo protegerlo de la presencia, sino también darlo como excluyéndolo de todo posible nombre.

${ }^{30}$ Solamente tratamos de describir esta paradoja de paradojas sin presuponer su efectividad, o sea, como una simple posibilidad. En nuestra opinión, la fenomenología no podrá decidir jamás la efectividad de estos fenómenos saturados por excelencia, pero sí podrá, por el contrario, concebir su posibilidad formal y describir la figura que tomarían estas paradojas de paradojas si finalmente irrumpen en nuestra vida, en nuestro mundo y en nuestra historia. Véase: Marion, J. L. (2010). "Métaphysique et phénoménologie. Une révèle pour la théologie", en Le visible et le révélé, Paris: Cerf.
} 
concebir fenomenológicamente la posibilidad formal del fenómeno Dios que se revela teológicamente de facto según la tercera vía, en la que se cumple, fuera de toda predicación, la teología mística?

Son tres las hipótesis que podemos admitir. Partiendo de Husserl, definimos el fenómeno por la dualidad indisociable entre el aparecer y el apareciente y admitimos que esta dualidad se despliega según la correlación entre la intenciónintuición, significación-cumplimiento y noesis-noema, con el fin de mostrar que hay tres posibles relaciones entre estos términos que entran en juego. En la primera relación, la intuición -cumplimiento- podría confirmar, al menos parcialmente, la intención -el concepto o la significación-. Esta igualdad tangencial definirá la adecuación entre el aparecer y el apareciente y, a su vez, evidenciará la verdad. Esta primera posible relación correspondería a la vía catafática, ya que esta procede mediante una afirmación conceptual justificada por la intuición. En la segunda relación, la intuición podría encontrarse sobreexcedida por la intención. En este caso, el fenómeno no entregará conocimiento objetivo por carecer de cumplimiento intuitivo. Esta segunda posible relación correspondería a la vía apofática, ya que esta procede mediante una negación conceptual pobre en intuición. Edmund Husserl tan solo admite estas dos posibles relaciones. Podemos confirmar, por tanto, que la fenomenología husserliana permanece aprisionada en el horizonte de la predicación $\mathrm{y}$, en consecuencia, dentro del ámbito de la "metafísica de la presencia".

Sin embargo, resta aún por analizar la tercera hipótesis. En esta posible tercera relación, la intuición -el cumplimiento- podría no adecuarse nunca a la intención -el concepto o la significación-, pero no porque el cumplimiento intuitivo esté ausente como en la segunda posible relación, sino porque la intuición sobrepasa sobremanera todo lo que el concepto pudiera acoger, exponer y comprender. Mientras que en la segunda relación el fenómeno no entregaba un conocimiento de objeto o una comprensión de sentido estricto por falta de cumplimiento intuitivo, ahora en la tercera relación tampoco lo entregará, pero no por carencia sino más bien por exceso de intuición. Se trata aquí de nuevo del fenómeno saturado. Ningún concepto, significación o intención podrá prever, organizar o contener aquello que el fenómeno saturado de intuición da. Pues, el exceso de intuición satura la medida de todo posible concepto. A partir de esta tercera relación podemos determinar la tercera vía, en la que se cumple, fuera de toda predicación y nominación, la teología mística.

Recordamos cómo en la tercera vía ninguna predicación o nominación parece posible. Con todo, añadimos ahora que esta derrota del conocimiento procede aquí explícitamente no de la ausencia de la intuición donadora sino precisamente de su exceso. Encontramos, de nuevo, una confirmación de todo ello en el pensamiento del Areopagita. Para él, el Dios que se da y se revela al hombre descalifica todo 
concepto, nombre o predicación que pudiera atribuírsele, puesto que "Él es más fuerte que todo discurso y todo conocimiento y sobrepasa, por tanto, la comprensión en general y por ello la esencia" (Areopagita, P.G. 3, 593a). Este exceso no solo vence la comprensión en general, sino también todo aquello que la lengua pudiera decir. De hecho, tanto los filósofos como los teólogos pueden alcanzar la des-nominación precisamente por esta carencia de significación decible y por la deficiencia del concepto y de la intencionalidad. Para Jean-Luc Marion (2010), p. 201, "Dios permanece incomprensible, pero no imperceptible, sin concepto adecuado, no sin intuición donadora". De este modo, la proliferación infinita de los nombres divinos solo muestra que estos son tan insuficientes como los conceptos que ponen en juego. En consecuencia, la des-nominación que cumple la tercera vía no tiene en absoluto nada que ver con la suficiencia del concepto - vía afirmativa- ni con la insuficiencia de la intuición -vía negativa-, sino, más bien, trata de testificar la insuficiencia inevitable de todo concepto, de toda predicación y de toda posible nominación.

Pero una objeción puede alzarse aquí. Pues, ¿cómo podría el exceso de intuición donadora revelar el fenómeno Dios cuando, en este caso, mucho más que en otros, la evidencia atestigua precisa y paradójicamente que Dios no se da nunca intuitivamente? Obviamente, bajo el modo de la paradoja. Ahora bien, adentrarnos en esta cuestión supondría abandonar la posibilidad formal del fenómeno Dios correspondiente a la tercera vía para considerar en adelante su eficacia. Subrayaremos con ahínco que la paradoja alcanza su más relevante grado de fenomenicidad en el advenimiento de Dios como fenómeno. De hecho, el fenómeno Dios, en tanto que paradoja de paradojas, no se somete jamás a las condiciones de posibilidad de la experiencia del objeto. Es más, se trata de una exigencia propia de la fenomenicidad de Dios el contradecir la experiencia del tipo del objeto, incluso, la del ente.

El filósofo francés propone dos figuras en las que se aprecia con claridad el exceso de intuición donadora. Primeramente, este exceso se cumple bajo la figura del estupor. El exceso de intuición provoca en el hombre un cierto pasmo ante la incomprensibilidad de Dios. ${ }^{31}$ Ciertamente, el hombre se encuentra completamente abierto a la fenomenicidad divina, pues el acceso a ella no está prohibido para el hombre. Sin embargo, es el propio hombre quien se impide a sí mismo avanzar e incluso permanecer en la fenomenicidad de Dios a causa del exceso de intuición donadora que el fenómeno Dios impone en su donación al hombre. Este permanece aturdido, congelado, desbordado por una demasía que no logra alcanzar ni

\footnotetext{
31 "Dios permanece incomprensible, es lo que quería mostrar aquí, no solo para los Querubines y Serafines, sino también para los Principados y Potestades y todas las especies de potencia creada, sino que nuestro conocimiento falla, menos bajo el nombre, que ante el terror que nos inspiran las cosas por decir. Porque el alma tiembla y se estremece cuando se aplica frecuentemente a contemplar las cosas de lo alto" (Crisóstomo, P.G. 48, 725).
} 
comprender. Por consiguiente, el estupor "testifica, en el modo de la prohibición, el exceso insistente e insostenible de la intuición de Dios" (Marion, 2010, p. 202). Finalmente, el exceso de intuición donadora se cumple nuevamente bajo la figura de la obsesión. El hombre permanece - extrañamente- obsesionado por el exceso de intuición que lo lleva continuamente a evocar, discutir, e incluso negar aquello de lo que admite no tener ningún concepto apropiado.

\section{CONCLUSIÓN}

Afirmamos, por tanto, que Dios ya no se manifiesta según el ser, sino que Dios adviene trascendiendo el ser como una presencia que permanece a distancia. De ahí que neguemos toda posible demostración racional de la existencia de Dios, pues ¿cómo podría un pensamiento creado y finito demostrar racionalmente la existencia de Dios, el cual no solo está más allá del ser, sino que, también, se manifiesta de otro modo que ser? Así lo ha intentado constantemente la esencia onto-teo-lógica de la metafísica, fracasando en cada uno de sus múltiples esfuerzos en los que ha intentado limitar, cosificar o aprehender a Dios bajo un concepto, una idea o un pensamiento racional creado y finito.

Ya desde la Kritik der reinen Vernunft de Immanuel Kant, el pensamiento no puede hacerse cargo de la omnitudo realitatis, esto es, de la enormidad de materia que sería necesaria reunir y captar por el pensamiento para rellenar la forma pura a priori del ideal de la razón pura que es Dios. De este modo, tanto la esencia onto-teo-lógica de la metafísica como toda posible teodicea o toda pretensión por demostrar racionalmente la existencia de Dios fracasa en su intento.

Pero ¿por qué la tradición filosófica se ha obstinado a lo largo de casi toda su historia en demostrar racionalmente la existencia de Dios y no, en cambio, mostrar, o mejor aún, dejar mostrarse a Dios en su propia manifestación, sin limitar su fenomenicidad y reducirlo bajo un concepto o una idea? Es aquí donde la fenomenología entra en juego. Así, pues, en el intento de pensar bajo un modo no metafísico, esto es, bajo un modo fenomenológico, ya no se trata de demostrar sino de mostrar, o más concretamente, de dejar aparecer. El fenómeno Dios ostenta el privilegio de hacerse ver, de manifestarse, de mostrarse, puesto que su aparición se manifiesta a partir de ella misma y como ella misma en su apariencia según su aparecer. 


\section{BIBLIOGRAFÍA}

Areopagita, D. (1857). P.G. 3: Opera Omnia. En Migne, J. P. (ed.). Paris: Migne.

Atanasio (1857). P.G. 25: Oratio contra gentes. En Migne, J. P. (ed.). Paris: Migne.

Bourgoing, F. (1644). "Préface”. En CEuvres complètes du Cardinal de Bérulle. Paris: Migne.

Bruaire, C. (1974). Le droit de Dieu. Paris: Aubier-Montaigne.

Crisóstomo, J. (1862). P.G. 48: De incomprehensibili Dei natura. En Migne, J. P. (ed.). Paris: Migne.

Damasceno, J. (1864). P.G. 94: Expisitio Fidei Orthodoxae. En Migne, J. P. (ed.). Paris: Migne.

Derrida, J. (1967). La voix et le phénomène. Paris: PUF.

Derrida, J. (1972). "La différance”. En Marges de la philosophie. Paris: Ed. de Minuit.

Derrida, J. (1987). “Comment ne pas parler. Dénégations”. En Psyché. Inventions de l'autre. Paris: Galilée.

Derrida, J. (1990). Le problème de la genèse dans la philosophie de Husserl. Paris: PUF.

Derrida, J. (1993). Sauf le nom. Paris: Galilée.

Derrida, J. (1997). “Carta a un amigo japonés”. En El tiempo de una tesis. Deconstrucción e implicaciones conceptuales. Barcelona: Ediciones Proyecto A.

Descartes, R. (1996). Meditationes de prima philosophica. En Adam, C. \& Tannery, P. (ed.). Paris: J. Vrin.

de Aquino, T. (1953). Quaestiones disputatae. Taurini: Marietti.

de Aquino, T. (1994). Summa Theologiae. Madrid: BAC.

de Hipona, A. (1843). P.L. 32: De ordine. En Migne, J. P. (ed.). Paris: Migne.

de Hipona, A. (1843). P.L. 38: Sermo. En Migne, J. P. (ed.). Paris: Migne.

de Lubac, H. (1945). De la connaissance de Dieu. Paris: Ed. de Temoignage Chrétien.

de Nisa, G. (1863). P.G. 44: De vita Moysis. En Migne, J. P. (ed.). Paris: Migne.

de Poitiers, H. (1845). P.L. 10: De trinitate. En Migne, J. P. (ed.). Paris: Migne.

García-Baró, M. (2009). Sócrates y herederos. Salamanca: Sígueme.

Justino (1857). P.G. 6: Apologia prima pro Christianis. En Migne, J. P. (ed.). Paris: Migne.

Levinas, E. (1979). Le temps et l'autre. Paris: Fata Morgana.

Levinas, E. (1994). Dios, la muerte y el tiempo. Madrid: Ediciones Cátedra.

Marion, J.L. (1977). L’idole et la distance. Paris: Ed. Grasset \& Fasquelle.

Marion, J.L. (2010). De surcroît. Études sur les phénomènes saturés. Paris: PUF.

Martín, C. (2001). Kena Upaniṣad. Madrid: Trotta. 
Orígenes (1857). P.G. 11: Liber primus. En Migne, J. P. (ed.). Paris: Migne.

Porcel, M. (2015). “¿Son realmente onto-teo-lógicas las pruebas clásicas de la existencia de Dios?” Proyección: Teología y mundo actual, 259, pp. 423-444.

Sales, M. (1970). "La théologie négative: méthode ou métaphysique”. Axes, III/2.

Solignac, A. (1990-1901). Dictionnaire de spiritualité. Paris: Beauchesne.

Spinoza, B. (1915), Ethica. Bari: Gius Laterza \& Figli.

Viola, C. E. (1972). "Les journées internationales anselmiennes”. Archives de Philosophie 35 (1), pp. 149-157. 